\title{
Role of availability of critical aquaculture inputs and community-managed markets on community-based floodplain wetland management
}

\author{
R. C. Barman ${ }^{1 *}$, Devashish K ar ${ }^{2}$, S. S. Dana ${ }^{3}$ and D. M aj umdar ${ }^{4}$ \\ 1,2Department of Life Science, Assam (Central) University, Silchar-11 (Assam), INDIA \\ ${ }^{3}$ Department of Fishery Extension, West Bengal University of Animal and Fishery Science, Kolkata, INDIA \\ ${ }^{4}$ Department of Agricultural Statistics, Bidhan Chandra Krishi Viswavidyalaya, Nadia (West Bengal), INDIA \\ *Corresponding author. E-mail: ramen67@gmail.com, rijuhc@ rediffmail.com \\ Received: M arch 19, 2011; Revised received: J anuary 12, 2012; Accepted: J uly 8, 2012
}

\begin{abstract}
India has extensive wetlands of 2.02 lakh ha. These are basically low-lying floodplain areas. Assam has endowed huge floodplain wetlands and are locally called as Beel. These are one of the most important fishery resources of India providing livelihood to thousands of poor people. The average existing fish production of Assam Beel is only $173 \mathrm{~kg} / \mathrm{ha} /$ year against its production potential of $1000-1500 \mathrm{~kg} / \mathrm{ha} /$ year. A study was conducted in three Beels of the Assam state to see the role of two situational independent variables namely availability of critical aquaculture inputs $\left(X_{1}\right)$ and community-managed markets $\left(X_{2}\right)$ on dependent variable i.e. knowledge levels of Beel users for community-based Beel fisheries management $(Y)$. The study revealed that community-managed markets was significantly and positively associated $(P<0.01)$ with knowledge levels of Beel users on community-based Beel fisheries management. Also, between these two variables, community managed market $\left(X_{2}\right)$ was found to be most significantly contributing variable ('t'-value $-2.91^{* \star}$ ) on knowledge levels of Beel users for community-based Beel fisheries management $(\mathrm{Y})$.
\end{abstract}

Keywords : Beel, Community based-fisheries management, Wetlands

\section{INTRODUCTION}

India has extensive wetlands of 2.02 lakhs ha (Sugunan and Bhattacharya, 2000). These are low-lying areas and situated in the floodplains of major rivers like Ganga ,Brahmaputra , Barak, Godavari, Cauvery and Krishna river basins. So, they are also called as floodplains wetlands (Shrivastava and Bhattacharjya, 2003; Kar, 2007, 2010). They are one of the most important fishery resources in the state of Assam, West Bengal, Bihar, Manipur, Arunachal Pradesh and Meghalaya (Vass, 1997; Sugunan and Bhattacharjya, 2000; Shrivastava and Bhattacharya, 2003; Barman et al., 2008) and provide livelihood to thousands of poor people. Assam has more than 1.0 lakh ha of floodplain wetland and are locally called as Beel.

Assam Beels constitute more than $70 \%$ of the total lentic water of the state. The average existing fish production of Assam Beel is $173 \mathrm{~kg} / \mathrm{ha} /$ year against its production potential of $1000-1500 \mathrm{~kg} / \mathrm{ha} /$ year (Shrivastava and Bhattacharjya, 2003; Kar, 2007, 2010). This reveals that the potential utilization of the B eel s have not been utilized leading to poor fish production of the state. Barman (2004) and Barman et al. (2008) indicated that situation variables like availability of critical inputs and transportation and marketing facilities were positively and significantly associated with the knowledge level of
Beel users for sustainable development of Beel fisheries. The community-based fisheries management may be the viable alternative in this regard.

The exiting knowledge level of Beel users plays a significant role on successful implementation of the community-based fisheries management. Accordingly, present study was conducted to see the relationship of two situational independent variables viz. availability of critical aquaculture inputs $\left(\mathrm{X}_{1}\right)$ and community-managed markets $\left(\mathrm{X}_{2}\right)$ with dependent variable i.e. knowledge levels of Beel users on community-based Beel fisheries management $(\mathrm{Y})$.

\section{MATERIALS AND METHODS}

The study was undertaken at the three Beels namely Kutuha Bar Beel (16.00 ha) in Dibrugharh district,Amuguri Basa Pathar Beel (49.80 ha) in Golaghat district and Talu Malu B eel (22 ha ) in Dhubri district of province of Assam . 200 house holds represented by both male and female, were randomly selected from the surrounding three Beels and were taken as the sample size of the study. Data were collected during 2007-2009 with the help of personal interview through structured interview schedule. Initially, data were collected through local language and replies were recorded simultaneously in English. Correlation matrix was prepared. Afterwards, correlation coefficient, regression analysis were used to analyze data using soft 
ware Statistical Package for Social Sciences (SPSS.Ver.7.50).

For measurement of dependent variable (Y), scale developed by Dana (1987), Sheikh et al. 1993), Barman (2004), Barman et al. (2008) was taken into consideration with necessary modifications. Respondents were grouped into in three categories (Tables 1, 2 and 3) viz. low, medium and high based on mean standard deviation and their knowledge score on community based fisheries management. Also, for making simple comparison, frequency tables were constructed and percentages were calculated.

\section{RESULTS AND DISCUSSION}

The study revealed that majority i.e. 146 (73\%) Beel users obtained medium availability of critical input scores followed by $36(18 \%)$ low availability critical input scores and only 18 (9\%) had obtained high availability critical input scores (Table 1). Similarly, majority of the Beel users i.e. $181(90.5 \%)$ obtained medium scores followed by 11 $(5.5 \%)$ high score followed by 8 (4)\% low score on community-managed marketing (Table 2). Further, majority i.e. $100(50 \%)$ obtained medium knowledge scores followed by $52(26 \%)$ low knowledge scores and followed by $48(24 \%)$ medium knowledge scores in regards to Beel users' knowledge level community-based fisheries management (Table 3). Table 4 indicates basic features of the data through descriptive statistics under the study. Correlation analysis (Table 5) indicated that community managed marketing were positively and significantly correlated at 0.01 level of probability $(\mathrm{P}<0.01)$ with Beel user's with the knowledge level on communitybased fisheries management.

Regression analysis revealed that community- managed marketing was found to be most significantly contributing variables that could explain the maximum variability of Beel users' knowledge level on community based fisheries management (' $\mathrm{t}$ ' values $2.91^{* *}$, significant at $1 \%(\mathrm{P}<0.01)$ level of significance on Beel users knowledge level).

Availability of aquaculture inputs and communitymanaged marketing are the essential elements for effective development of fishery and aquaculture. Under the community-managed marketing system, Beel users are free to procure their aquaculture inputs by themselves as per their choice, need and satisfaction and even at the low cost. Because, there is no involvement of middlemen in overall procurement and marketing. These inputs may be quality fish seeds, different organic and inorganic fertilizers to produce quality fish seeds and table fish, prophylactic and therapeutic drugs, fishing equipments, etc. Community-managed marketing can also bring 'ownership status' and 'we feelings' with respect to management of Beel fisheries through direct involvement of Beel users in each stage of procurement and marketing. The study also clearly indicated that communitymanaged marketing is most important situational variables for successful community-based fisheries

Table 1. Distribution of respondents according to availability of critical inputs $(\mathrm{N}=200)$.

\begin{tabular}{|c|c|c|c|c|c|}
\hline \multicolumn{3}{|l|}{ Category } & \multicolumn{2}{|r|}{ Frequency } & $\%$ \\
\hline \multicolumn{3}{|c|}{ High availability of critical inputs scores ( up to 9 out of 15 ) } & \multicolumn{2}{|r|}{18} & 9 \\
\hline \multicolumn{3}{|c|}{ Medium availability of critical inputs scores $(>9$ and $<12$ out of 15$)$} & \multicolumn{2}{|r|}{146} & 73 \\
\hline \multicolumn{3}{|c|}{ Low availability of critical inputs scores (> 12 out of 15 ) } & \multicolumn{2}{|r|}{36} & 18 \\
\hline \multicolumn{6}{|c|}{ Table 2. Distribution of respondents according to community-managed marketing (N 200). } \\
\hline \multicolumn{3}{|l|}{ Category } & \multicolumn{2}{|r|}{ Frequency } & $\%$ \\
\hline \multicolumn{3}{|c|}{ Low score on community-managed marketing $(<15$ out of 30$)$} & \multicolumn{2}{|r|}{11} & 5.5 \\
\hline \multicolumn{3}{|c|}{ Medium score on community-managed marketing (15-25 out of 30 ) } & \multicolumn{2}{|r|}{181} & 90.5 \\
\hline \multicolumn{3}{|c|}{ High score on community-managed marketing ( $\geq$ out of 30 ) } & \multicolumn{2}{|r|}{8} & 4.0 \\
\hline \multicolumn{6}{|c|}{ Table 3. Distribution of respondents according to knowledge level on community-based fisheries management (N=200). } \\
\hline \multicolumn{3}{|c|}{ Frequency } & \multicolumn{3}{|c|}{ Percentage } \\
\hline \multicolumn{2}{|l|}{ High knowledge scores (more than 85) } & 48 & \multicolumn{3}{|c|}{24} \\
\hline \multicolumn{2}{|l|}{ Medium knowledge scores (75-80) } & 100 & \multicolumn{3}{|c|}{50} \\
\hline \multicolumn{2}{|l|}{ Low knowledge scores $(<75)$} & 52 & \multicolumn{3}{|c|}{26} \\
\hline \multicolumn{6}{|c|}{ able 4. Descriptive statistics indicating basic features of data. } \\
\hline & Minimum & Maximum & M ean & \multicolumn{2}{|c|}{ Std. deviation } \\
\hline Availability of critical aquaculture inputs & 6.000 & 18.000 & 10.380 & \multicolumn{2}{|c|}{1.580} \\
\hline Community-managed markets & 7.000 & 26.000 & 19.810 & \multicolumn{2}{|c|}{3.370} \\
\hline $\begin{array}{l}\text { Knowledge level of Beel users on community- } \\
\text { based fishery management }\end{array}$ & 51.000 & 96.000 & 79.420 & \multicolumn{2}{|c|}{8.570} \\
\hline
\end{tabular}


Table 5. Correlation of different predictors' situational variables with knowledge level of B eel users on community-based fisheries management.

\begin{tabular}{llc}
\hline S. No. code & Predictor situational variables & ' $\mathrm{r}^{\prime}$ values \\
\hline $\mathrm{X}_{1}$ & Availability of critical inputs & -0.020 \\
$\mathrm{X}_{2}$ & Community-managed marketing & $0.387^{* *}$ \\
\hline
\end{tabular}

** =Significant at 0.01 level of probability $(\mathrm{P}<0.01)$

management. Similar findings have also been reported by Dana (1987), Barman (2004) and Barman et al. (2008).

\section{Conclusion}

From the study it is concluded that community-managed markets was significantly and positively associated with knowledge levels of Beel users on communitybased Beel fisheries management. Also, between these two variables, community-managed market was found to be most significantly contributing variable on knowledge levels of Beel users for community-based Beel fisheries management. This reveals that this variable is the one of the important factors for sustainable development and management of Beel fisheries through community-based Beel fisheries management program.

\section{ACKNOWLEDGEMENT}

The authors are grateful to representative of North East Affected Area Development Society (a north east based Non- Government Organization), Dibrugarh and Golaghat and Gauripur Vivekananda Club, Dhubri (a local NGO) District for their cooperation and help during collection of data and supply of relevant information under the study. Authors are also grateful to the officials of District Fishery Department for their helps in all aspects during the study.

\section{REFERENCES}

Barman, R.C.(2004). Community-based fisheries management with peoples participation for sustainable development of Beel fisheries. M.F.Sc Thesis, West Bengal University of Animal and Fisheries Sciences, Mohanpur, West Bengal, Nadia.

Barman, R.C., Dana, S.S. Bhattacharjya, B. K., Kar, D. and Barbhuyan, A.H. (2008). Effect of situational variables on knowledge level of fishermen for sustainable development of Beel Fisheries. Environment \& Ecology, 26(4B): 2092-2094.

Dana, S. S. (1987). A study of factor affecting the attitude of livestock owners towards artificial insemination in cattle. M.V.Sc.Thesis, Indian Veterinary Research Institute, Izatnagar, Uttar Pradesh, pp. 127.

Kar, D. (2007). Fundamentals of Limnology \& Aquaculture Biotechnology. Daya Publishing House, Delhi.

Kar, D. (2010). Biodiversity Conservation Prioritisation. Swastik Publication, Delhi.

Sheikh, A. A., Arya, H. P. S. and Nikam, T. R. (1993). Knowledge level of farmers on poultry production technology. Indian J ournal of Extension E ducation, 29 (3 and 4): 92-93.

Shrivastava, N. P. and Bhattacharya, B. K. (2003). Status of fisheries of floodplain wetlands of Assam. In. Vinci, G. K., Jha, B. C., Bhaumik, U. and Mitra, K. (Ed) Fisheries management of floodplain wetlands in India (pp. 22-29), Bull. No. 125, Central Inland Fishery Research Institute (CIFRI), ICAR, Barrackpore.

Sugunan, V. V. and Bhattacharjya, B. K. (2000). E cology and fisheries of B eels in Assam. Bull. No. 104. CIFRI, ICAR, Barrackpore.

Vass, K.K.(1997). Floodplain wetlands-an important inland fishery resource of India. In : Fisheries enhancement of small reservoir and floodplain lakes in India (pp.23-30). CIFRI, ICAR, Barrackpore, West Bengal, India. 